\title{
THE ROLE OF BLOCKCHAIN TECHNOLOGY IN SMART CITY
}

\author{
Manish Verma \\ Scientist D \\ DMSRDE, DRDO, Kanpur, India
}

\begin{abstract}
In late decades, the fast development of urbanization gives a huge headways in creating proficient, astute and practical arrangements. Keen city needs these arrangements in giving better administration of waste, water, electricity, land and different e-administration administrations. In this paper, Blockchain technology utilization for smart cities has been discussed.
\end{abstract}

Keywords - Blockchain, Distributed ledger, Emerging Intelligence based application, smart city, Peer-to-peer network

\section{INTRODUCTION}

Prime Minister of India propelled "100 Smart Cities Mission" on 25 June 2015. An aggregate of $₹ 98,000$ crore (US\$14 billion) was endorsed by the Indian Cabinet for the improvement of 100 perceptive urban communities and the restoration of 500 others. ₹ 48,000 crore (US $\$ 6.7$ billion) for the Smart Cities crucial an all out financing of $₹ 50,000$ crore (US\$7.0 billion) for the Atal Mission for Rejuvenation and Urban Transformation (AMRUT) have been affirmed by the Cabinet.

In the 2014 Indian government dispensed ₹7,016 crore (US\$980 million) for the 150 keen urban communities. Notwithstanding, just ₹924 crore (US\$130 million) of the allotted sum could be spent until February 2015. Henceforth, the 2015 Union financial plan of India assigned just ₹143 crore (US\$20 million) for the task.

The primary bunch of 20 urban areas was chosen. Known as 20 Lighthouse Cities in the first round of the All India City Challenge rivalry, they will be given focal help of ₹200 crore (US\$28 million) each during this monetary year followed by $₹ 100$ crore (US\$14 million) every year during the following three years. The Urban Development Ministry had before discharged ₹2 crore (US\$280,000) each to mission urban communities for planning of Smart City Plans.

\section{BLOCKCHAIN}

Blockchain utilizes the conveyed record innovation (DLT), which implies that information is never spared at one spot, however across hubs or clients. While not all Blockchain works along these lines, about all utilizations of Blockchain are nailed to its circulated record tech. This keeps each hub or client side by side of the improvements over the chain as in figure 1. Exchanges are recorded as far as squares which are included simply after a confirmation and approval process done either through Proof-of-Stake or Proof-of Work. The squares once included cannot be expelled or adjusted, which makes Blockchain more secure than paper documentation, customary databases and different choices.

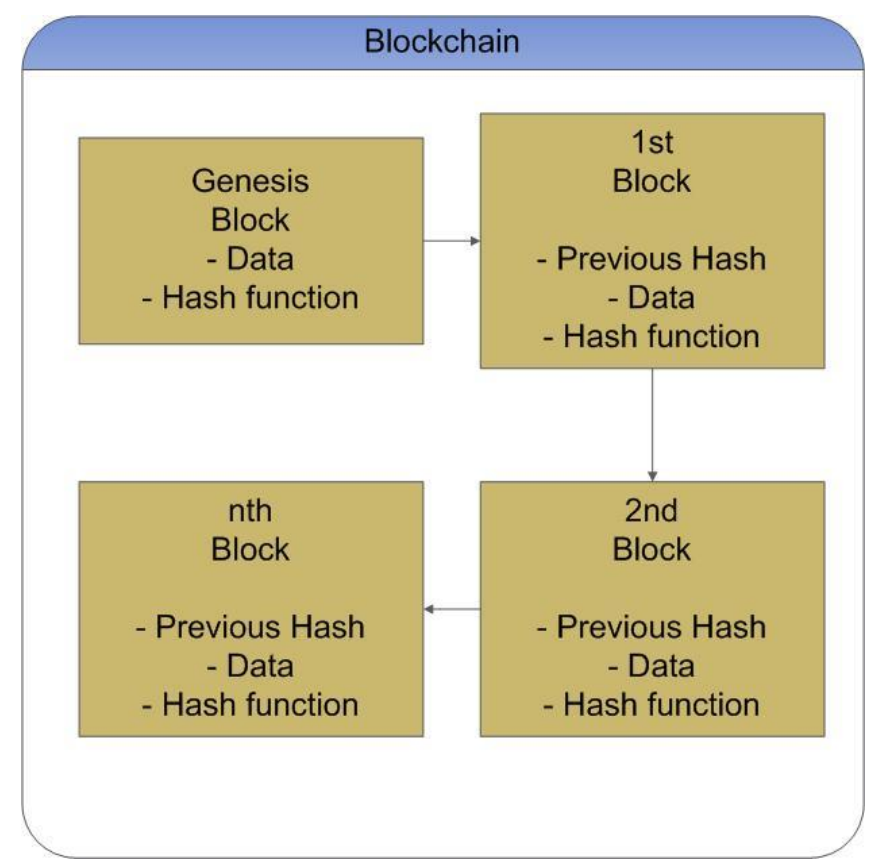

Figure 1: Blockchain technology with various squares

This not just wipes out the requirement for an outsider reviewer yet in addition dismiss the chance of anybody altering or controlling the information. There is a $51 \%$ assault plausibility where the conventions could be changed, if enough hubs follow up on it, nonetheless, even this is recorded and effectively recognizable to the hubs that put this moving.

\section{SMART CITY MANAGEMENT SYSTEM BASED ON BLOCKCHAIN TECHNOLOGY}

The smart city idea coordinates data and correspondence innovation (ICT), and different physical gadgets associated with the IoT system to improve the effectiveness of city activities and administrations and interface with residents. 


\section{International Journal of Engineering Applied Sciences and Technology, 2021 \\ Vol. 5, Issue 11, ISSN No. 2455-2143, Pages 226-228 \\ Published Online March 2021 in IJEAST (http://www.ijeast.com)}

Smart city innovation permits city authorities to communicate straightforwardly with both network and city framework and to screen what is going on in the city and how the city is developing. ICT is utilized to improve quality, execution and intuitiveness of urban administrations, to lessen expenses and asset utilization and to expand contact among residents and government. Keen city applications are created to oversee urban streams and take into account ongoing reactions. A smart city may in this way be more arranged to react to difficulties than one with a straightforward "value-based" relationship with its residents. However, the term itself stays muddled to its particulars and in this manner, open to numerous translations.

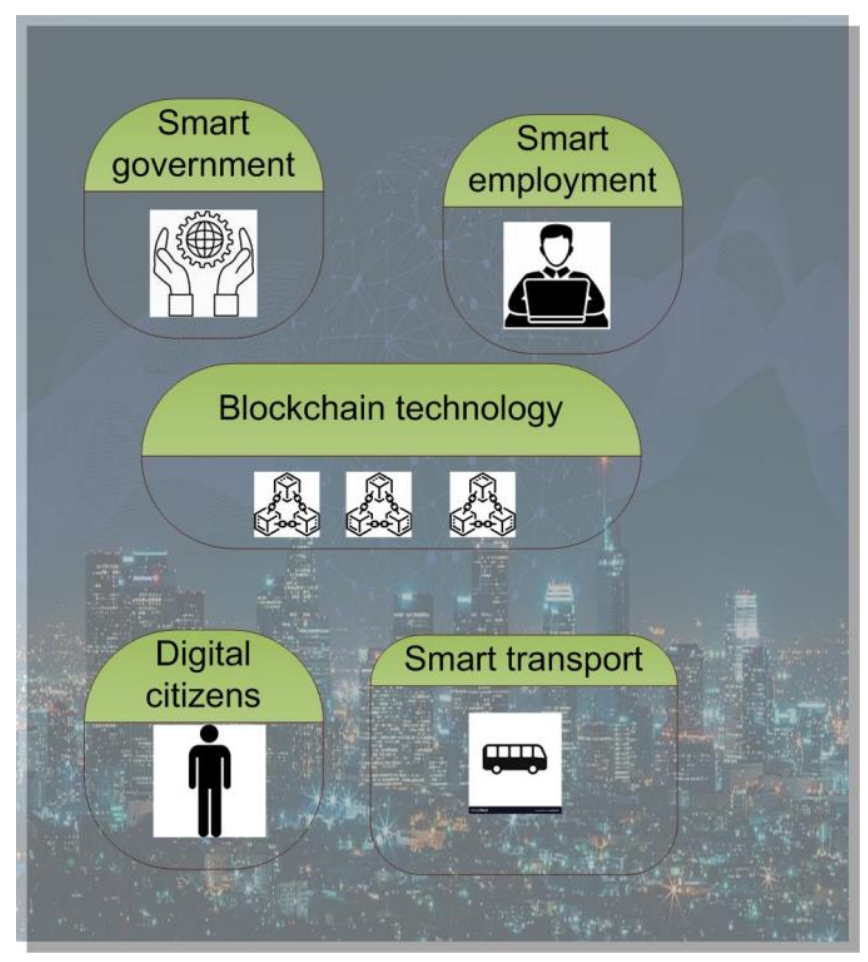

Figure 2: Smart city with Blockchain technology

Blockchain innovation permits city the board to be circulated among all gatherings included. The decentralized administration made conceivable by this methodology could be the way to taking care of different socio demographic issues that are on the ascent.

Numerous investigations have anticipated that the eventual fate of the planet will be in a general sense urban. Current patterns show that individuals are migrating to urban communities' altogether. By 2025, almost $70 \%$ of the worldwide populace will live in urban zones. The urban way of life will be the fundamental motor of the worldwide economy, yet it will likewise be the planet's most prominent wellspring of unreasonableness. Contamination, weight on water assets, and social disparities are only a couple of the issues approaching not too far off. The idealistic view is that urban communities are the world's advancement lab_ as they have been from the beginning of time - and can in this way be relied upon to create arrangements in different circles that characterize the nature of urban life: foundation, transport, social insurance administrations, training, relaxation, wellbeing, and so on.

Blockchain is a layer that can wrap these different parts together. Development in this field is hence a problem that needs to be addressed. Regional authorities will have a place with everybody. Like general society and private partners referenced above, conventional residents are eager for cooperation, majority rules system, and straightforwardnessthree key ideas that go connected at the hip with the innovation behind bitcoin.

\section{CONCLUSION}

The Blockchain based smart cities would become basic method of city management for administrators in future environment. It would be city management system and Blockchain based record keeping and verification that will key pillar of any smart city.

\section{REFERENCE}

[1] Bernard Zoë. (2018) Everything you need to know about Bitcoin, its mysterious origins, and the many alleged identities of its creator. Business Insider.

[2] Finley Klint. (2018) After 10 Years, Bitcoin Has Changed Everything-And Nothing.

[3] Nakamoto Satoshi. (2008) Bitcoin whitepaper. URL: https://bitcoin.org/bitcoin.pdf

[4] Nakamoto Satoshi. (2009) Bitcoin v0.1 released. The Mail Archive 9.

[5] Maesa, Damiano Di Francesco, Paolo Mori, and Laura Ricci. (2017) Blockchain based access control. IFIP international conference on distributed applications and interoperable systems. Springer, Cham.

[6] Biswas Kamanashis, and Vallipuram Muthukkumarasamy. (2016) Securing smart cities using blockchain technology. 2016 IEEE 18th international conference on high performance computing and communications.

[7] Verma Manish. (2021) Smart contract model for trust based agriculture using blockchain technology, in International journal of research and analytical reviews, Vol 8 Issue 2, April 2021 (pp. 354-355)

[8] Sun Jianjun, Jiaqi Yan, and Kem ZK Zhang. (2016) Blockchain-based sharing services: What blockchain technology can contribute to smart cities. Financial Innovation 2.1, (pp. 1-9).

[9] Pieroni Alessandra, et al. (2018) Smarter city: smart energy grid based on blockchain technology. Int. J. Adv. Sci. Eng. Inf. Technol 8.1, (pp. 298-306). 
[10] Nam Kichan, et al. (2019) Blockchain technology for smart city and smart tourism: latest trends and challenges. Asia Pacific Journal of Tourism Research (pp. 1-15).

[11] Xie Junfeng, et al. (2019) A survey of blockchain technology applied to smart cities: Research issues and challenges. IEEE Communications Surveys \& Tutorials 21.3 (pp. 2794-2830).

[12] Rivera, Rogelio, et al. (2017) How digital identity on blockchain can contribute in a smart city environment. 2017 International smart cities conference (ISC2). IEEE, .

[13] Sharma Pradip Kumar, and Jong Hyuk Park. (2018) Blockchain based hybrid network architecture for the smart city. Future Generation Computer Systems 86 (pp. 650-655).

[14] Zhou Q., Huang H., Zheng Z., \& Bian J. (2020). Solutions to scalability of blockchain: A survey. IEEE Access, 8, (pp. 16440-16455). 